\title{
Citizen science: Exploring its application as a tool for prodromic surveillance of vector-borne disease
}

\author{
Hines $D^{1 *}$, Sibbald $S L^{1,2,3}$ \\ ${ }^{1}$ The Schulich Interfaculty Program in Public Health, Western University, London, ON \\ ${ }^{2}$ Department of Medicine, Western University, London, ON \\ ${ }^{3}$ School of Health Studies, Western University, London, ON \\ "Correspondence: dhines6@alumni.uwo.ca
}

\section{Abstract}

Citizen science is the systematic collection and analysis of data, development of technology, testing of natural phenomena and the dissemination of these activities by researchers on a primarily avocational or voluntary basis. The application of citizen science-informed mobile applications (apps) provides a means for Canadians to participate in the surveillance of infectious disease.

This article makes the case for a mobile application that can be used to enhance the surveillance of vector-borne diseases in Canada. Lyme disease is used as an example due to its increasing incidence and lack of available real-time information. The authors also suggest how such an app could be designed and used in a way that would attract end users to download and use it as a public health tool. If successful, these type of apps could serve as supplements to active surveillance programs as well as a means for bidirectional communication between public health professionals and citizens.

\section{Introduction}

In the past decade, climate change and public health have become inextricably linked (1). A recent survey, reported that over $81 \%$ of Canadians were concerned about health risks associated with climate change. The same survey showed that $49 \%$ of Canadians felt climate change increased the incidence of infectious disease (2). As the Canadian climate continues to warm, tick and other vector populations are beginning to increase, most notably in areas such as Southern British Columbia and Ontario (3). Lyme disease is the most common vectorborne zoonosis in North America and is on the rise across Canada. It was estimated that in $2010,18 \%$ of the population of Eastern and Central Canada were living in areas at risk of Lyme disease and this percentage is projected to increase $(4,5)$.

The Ixodes black legged tick known to carry the Lyme disease causing bacteria Borrelia burgdorferi, is distributed across Canadian deciduous or mixed forests habitats (6). In addition to Lyme disease, cases of vector-borne diseases uncommonly identified in Canada are beginning to present closer to Canadian borders. For example, in 2014 the United States Centers for Disease Control and Prevention (CDC) reported the first cases of two tickborne diseases (Powassan virus, known to produce long-term neurological problems and Anaplasmosis, a disease with typical symptoms of fever and headache) in the Great Lakes region (7).

Infectious disease surveillance in Canada has successfully identified the appearance and spread of infectious diseases such as Influenza H1N1, H7N9, SARS, Lyme disease and others. Increasing available 'real-time' information on these diseases could improve public health officials' understanding of a potential outbreak and also provide public education. Ideally, the collection of real-time information should be a collective effort. The recent Ebola outbreak has led to exploration of how smartphone user activity could be used to track disease spread (8). At this time smartphone user activities are monitored retroactively, whereas citizen science could inform processes for real-time monitoring of disease spread (8). 
Citizen science has been defined by Kinder as, "the systematic collection and analysis of data, development of technology, testing of natural phenomena and the dissemination of these activities by researchers on a primarily avocational basis" (9). Simply put, it is citizen observations or data that is collected on a volunteer basis. Citizen science is a fairly new term, but is an old practice $(10,11)$. In recent years, researchers have used citizen science, in their work to support findings described in publications or presentations $(10,12,13)$.

Incorporating citizen involvement in the surveillance or raising awareness of vector-borne disease, such as Lyme disease, could be a novel form of citizen science. This could be achieved through the use of a mobile phone application designed to collect information on vector habitats or breeding grounds. To the authors' knowledge, a smartphone app allowing for bidirectional flow of vector-borne disease information (from end user to administrator and vice versa), has not yet been developed (14).

It is proposed that citizen science-informed applications should be developed to raise awareness of notifiable vector-borne disease. In doing so, they could empower the community and aid in the protection of public health. This commentary explores how the collective power of smartphone users could be harnessed to support awareness and surveillance of vector-borne disease.

\section{Analysis}

It is very difficult to accurately track vector-borne diseases, such as Lyme disease in real-time (i.e., the actual time during which an event occurs). Tracking and identifying areas endemic with Ixodes blacklegged ticks carrying $B$. burgdorferi requires a significant number of hours and is often challenged by many other competing demands on public health officials. This challenge could be reduced by recruiting the assistance of public citizens in collecting this information. Engaging citizens via mobile applications where citizens can observe natural events and be linked to scientific research on a particular vector-borne disease provides an opportunity for public participation in the protection of public health.

Smartphone usage among Canadian adults (18-65 years of age) is on the rise. In 2013, a Google report estimated that $56 \%$ of adults were using a smartphone, up from $33 \%$ in early 2012 (15). Google Canada indicated smartphone users "are using their mobiles to change the way they communicate with others and specifically trying to understand the world around them" (16). The increased use of mobile devices and their applications has expanded Canadians' ability to participate in and protect the health of their communities. Mobile applications grounded in the concepts of citizen science (9) present a viable option to mobilize citizens in the surveillance of and awareness-raising efforts about vector-borne diseases.

\section{Citizen science, mobile applications and health}

Smart phone technology allows a natural extension of citizen science with the added benefit of being real-time. Much like the call for citizens to scan millions of images for clues in an attempt to solve the case of the missing Malaysian Airlines plane (17), incorporating citizen science functionality into a mobile application would provide an opportunity for citizens to engage in real-time prodromic (pre-diagnostic health information) vector-borne disease surveillance and potentially provide warnings for impending public health concerns.

An example of an app developed for infection surveillance is Flu near You designed by HealthMap at Boston's Children Hospital (18). This is a community-driven flu-tracking site that provides real-time information to the public. Another example of a public health-oriented app is ImmunizeON, an app designed to monitor, track and remind Ontarians of their immunization schedules (19). The app maintains vaccination records, alerts end users about immunization schedules and informs them about potential harms related to defective vaccines or other events of public health significance through the use of banners. ImmunizeON is an excellent app for monitoring and tracking, but it does not promote the collection and submission of observations and data. The communication function between end users and public health officials remains limited to emails through an external site and there is no user interface which allows for direct communication through the app itself. A citizen science-informed app would expand the communication functionality to include a way to allow submissions from end users back to public health.

The primary function of a citizen science-based Lyme disease app would be to provide citizens with information on how to identify ticks and their habitats. The Lyme disease mobile app developed by the Eastern Ontario Health 
Unit provides information on symptoms of Lyme disease, physical characteristics of the ticks and what to do if bitten (20), but it does not include the feedback loop to help track where ticks are located. By adding a geotagging capability (that is, the ability to track the exact geographic location of ticks), the end user could tag and take photos of prospective pathogen-carrying ticks. The final layer of functionality would be to have public health officials engage with the tags/photos in real-time. When public health officials receive submissions, a team of trained professionals could identify whether the submission warrants further investigation (i.e., is in fact a pathogen-carrying tick species). To the authors' knowledge, current available apps do not include the function of allowing citizens to submit photos or data.

Citizen science allows end users to interact with health professionals and submit observations that professionals themselves would not be able to. In the case of ImmunizeON, prodromic surveillance of potential adverse effects related to defective vaccines is possible by embedding a two-way communication functionality (i.e., In-App Messaging). A number of successful citizen science projects have been launched that demonstrate the potential of citizen science apps, such as National Moth Week 2014, which promotes contributing photos and data to online databases and Drexel University's Dr. Dan Duran's Elderberry Longhorn Beetle Project (13).

Theoretically, a citizen science-informed surveillance app, complete with diagnostic criteria for the vector in question, would allow citizens to confidently identify risk areas for ticks. This would occur as citizens were engaging in activities such as (hiking, hunting, gardening, etc.) in yards, parks or forests in or near known risk areas.

\section{Application development}

According to Google's Mobile Movement Report, $82 \%$ of smart phone users in Canada use their smart phones to research and read news and $27 \%$ look up health-related information. Smartphone users currently accessing health-related information would be a prime target audience for a citizen science-based app. However, the promotion for this application should be open to all who are interested as citizen science is not meant to focus solely on individuals or groups with subject knowledge. A citizen science-based app should be user friendly and targeted to even the most novice smartphone user.

\section{Considerations}

There are several key considerations when developing and launching a citizen science initiative (21). The first is the issue of incentives for use. Citizen science for the purposes of awareness and data/information collection is considered avocational and distinct from work that is compensated (9). Much of the software or "freeware" is distributed at no cost to the consumer with little or no restrictions on use (12). Attaching incentives (monetary or other) to the citizen science activity might increase participants' use, but would also introduce potential unintended consequences such as engagement for monetary gain (22).

"Gamifying" or the use of game design elements in non-game contexts (23) is a second consideration. By making the app fun to use, gamifying can help gain traction with participants by maintaining their engagement (24) as well as attracting and retaining users (23).

A third consideration is the promotion of the app. Usage of traditional multimedia advertising (television, social media, print ads etc.) and Web 2.0 (such as blogs and online forums) are reliable methods of promotion. Innovative social marketing tools such as RSS feeds (Rich Site Summary or Really Simple Syndication broadcasting information to external websites) are also useful in engaging a broad target audience.

There are other questions to consider when developing a platform for any citizen science-based tool. For example: Who will be responsible for managing the information (a vendor or public health agency? Who will fund the initiative (local, national private)? How will results be disseminated back to the end user and the broader public? 


\section{Conclusion}

Canada is witnessing an increase in vector-borne diseases due to climate change, modification of the ecology and other factors. A citizen science-informed mobile application could provide a creative medium to disseminate learning tools about vectors and vector-borne diseases and to interact with Canadians. Citizen science also has the potential to empower Canadians and maximize their ability to contribute to knowledge creation and health surveillance. If successful, a Lyme disease app could serve as a template to track other similar vector-borne disease (for example: Powassan virus and Anaplasmosis).

Citizen science is gaining traction in the mobile application and the academic sector and there are opportunities to explore its use in public health. Since an app to track and monitor vector-borne diseases has to the authors' knowledge, not been developed or evaluated, we cannot be sure that it would be successful, however we do know from the study of citizen science and through the use of other similar applications that engaging the community in this way could provide valuable potential in monitoring and raising awareness.

This commentary is part of a larger discussion around public participation in infectious disease surveillance. During disease outbreaks or pandemics, members of society may feel powerless and often rely on healthcare authorities for guidance and protection. Increased use of mobile devices in the Canadian population coupled with the rise of mobile news apps and social media could provide a point of access to augment capacity for real-time infectious disease surveillance.

\section{Acknowledgements}

Many thanks to Michel Deilgat for his excellent input and support on earlier versions of this article. Delaney Hines would like to thank the Master of Public Health program within the Schulich School of Medicine and Dentistry at Western University for arranging the placement opportunity at the Centre for Food-borne Enteric, Zoonotic and Infectious Disease at the Public Health Agency of Canada, where much of the ideas in this paper were developed.

\section{Conflict of interest}

None

\section{Funding}

None

\section{References}

(1) Maibach EW, Nisbet M, Baldwin P, Akerlof K, Diao G. Reframing climate change as a public health issue: An exploratory study of public reactions. BMC Public Health. 2010;10(1): 299.

(2) Akerlof K, Debono R, Berry P, Leiserowitz A, Roser-Renouf C, Clarke K, Rogaeva A, Nisbet MC, Weathers MR, Maibach EW. Public perceptions of climate change as a human health risk: Surveys of the United States, Canada and Malta. Int J Environ Res Public Health. 2010;7(6):2559-606.

(3) Public Health Agency of Canada [Internet]. Lyme disease and other tickborne diseases: Information for healthcare professionals. Ottawa: Government of Canada; 2014. http://www.phac-aspc.gc.ca/id-mi/tickinfo-eng.php\#sec-2.2.

(4) Leighton PA, Koffi JK, Pelcat Y, Lindsay LR, Ogden NH. Predicting the speed of tick invasion: An empirical model of range expansion for the Lyme disease vector Ixodes scapularis in Canada. J Appl Ecol. 2012;49:457-464.

(5) Ogden NH, Radojevic M,Wu X, Duvvuri VR, Leighton PA, Wu J. Estimated effects of projected climate change on the basic reproductive number of the Lyme disease vector Ixodes scapularis. Environ Health Perspect. 2014;122(6): 63138. http://ehp.niehs.nih.gov/1307799/.

(6) Hatchette TF, Davis I, Johnston BL. Lyme disease: Clinical diagnosis and treatment. CCDR. 2014;40(11):194-208. http://www.phac-aspc.gc.ca/publicat/ccdr-rmtc/14vol40/dr-rm40-11/dr-rm40-11-lyme-1-eng.php.

(7) Centers for Disease Control and Prevention [Internet]. Tickborne diseases of the U.S. Atlanta: Centers for Disease Control and Prevention, 14 July 2014. http://www.cdc.gov/ticks/diseases/.

(8) Talbot D. Cell-phone data could help predict Ebola's spread [Internet]. Boston: MIT Technology Review; 22 Aug. 2014. http://www.technologyreview.com/news/530296/cell-phone-data-might-help-predict-ebolas-spread/.

(9) Kinder J. Engaging Canadians in citizen science. Canadian Government Executive. 2014;20(4):15. http://www.canadiangovernmentexecutive.ca/category/item/1543-engaging-canadians-in-citizen-science.html. 
(10) Iii F, Mims M. Amateur science: Strong tradition, bright future. Science. 1999;284(5411):55-56. http://www.sciencemag.org/content/284/5411/55.full.

(11) Feyerabend P. Science in a free society. 4th ed. Vol. 31. London: Verso; 1978. p. 385-90.

(12) Cornell Lab of Ornithology - Citizen Science Central [Internet]. Defining citizen science. Ithaca: National Science Foundation; 2014. http://www.birds.cornell.edu/citscitoolkit/about/definition.

(13) Scientific American [Internet]. Citizen science. New York: Scientific American; 2014. http://www.scientificamerican.com/citizen-science/.

(14) Benedict M, Geleta D. Development of ClickClinica: A novel smartphone application to generate real-time global disease surveillance and clinical practice data. BMC Medical Informatics and Decision Making. 2013;13(1):70-80. http://www.biomedcentral.com/1472-6947/13/70.

(15) Ipsos MediaCT [Internet]. Our mobile planet: Canada - Understanding the mobile consumer. Google, May 2013. http://think.withgoogle.com/mobileplanet/en/.

(16) Canadian Broadcasting Corporation [Internet]. Smartphone use way up in Canada, Google finds. 29 July 2013.

(17) Martinez M, Williams D, Simon D. Crowdsourcing volunteers comb satellite photos for Malaysia Airlines jet. Cable News Network, 12 Mar. 2014

(18) American Public Health Association [Internet]. Flu near you: Do you have it in you? 20 Oct. 2014. https://flunearyou.org/about/.

(19) Wilson K, Atkinson K, Pluscauskas M, Bell C. A mobile-phone immunization record in Ontario: Uptake and opportunities for improving public health. J Telemed Telecare. 2014;1(5). http://www.ncbi.nlm.nih.gov/pubmed/25084770.

(20) Ontario Agency for Health Protection and Promotion (Public Health Ontario). Vector-borne diseases 2013 summary report. Toronto: Queen's Printer for Ontario; 2014. http://www.publichealthontario.ca/en/eRepository/Vector_Borne_Diseases_Summary_Report_2013.pdf.

(21) Archer G. Crowdsourcing: Improve healthcare with the brainpower of millions [Internet]. Action For Better Healthcare. 15 May 2014. http://actionforbetterhealthcare.com/crowdsourcing-improve-healthcare-brainpower-millions/.

(22) Kumagai D. Exploiting digital workers through global crowdsourcing. U of T News. Toronto: University of Toronto;11 Mar. 2014

(23) Deterding S, Dixon D, Khaled R, Nacke L. From game design elements to gamefulness: Defining gamification, In: Proceedings of the 15th International Academic MindTrek Conference: Envisioning future media environments. 2011;9(15). http://gamification-research.org/2012/04/defining-gamification/.

(24) Von Bargen T, Zientz C, Haux R. Gamification for MHealth: A review of playful mobile healthcare. Stud Health Technol and Inform. 2014;225(28). http://www.ncbi.nlm.nih.gov/pubmed/25000057. 